\title{
Vantagens da Implantação das Ipsas na Contabilidade Pública Brasileira: Análise da percepção dos membros do GTCON
}

\section{Resumo}

O estudo teve como objetivo avaliar a percepção dos membros do Grupo Técnico de Padronização de Procedimentos Contábeis (GTCON) quanto às vantagens da implantação das normas internacionais de contabilidade aplicadas ao setor público no Brasil. Para isso, fez-se uso de questionário elaborado sob cinco abordagens teóricas. O universo da pesquisa correspondeu aos participantes do GTCON. A amostra resultou de 108 respondentes, totalizando 27\% da população. Testou-se a confiabilidade do instrumento por meio de modelo definido por Cronbach (1951). Como cada dimensão teórica abordada é composta por múltiplas variáveis, realizou-se a redução da dimensionalidade dessas por meio da Análise dos Componentes Principais (ACP). Fez-se ainda uso de regressão linear múltipla, a partir dos componentes principais de cada construto teórico. A percepção das normas, a interpretação das normas, o custo-benefício da implantação e a responsabilidade educativa foram submetidas à análise como variáveis independentes, as vantagens da implementação das Ipsas foram submetidas como a variável dependente. Os principais resultados evidenciaram que os atores da pesquisa concordaram que a implantação das Ipsas é alvo capaz de ser alcançado. Quanto à análise custo-benefício da implantação, na visão do GTCON, a aplicação das Ipsas trará resultados superiores aos investimentos despendidos. Observou-se também que entrevistados não concordaram que o treinamento e a aplicação das Ipsas deva ser assegurado por esforços pessoais, mas, sim, pelo governo, ou seja, quanto mais o setor público se responsabilizar pela capacitação das normas, maiores serão as vantagens obtidas. Finalmente, o componente interpretação das normas, na visão do GTCON, não está ainda bem definido como e quem efetivamente vai ser responsável pela interpretação: os órgãos internacionais ou as instituições locais envolvidas no processo.

Palavras-chaves: Ipsas; GTCON; Contabilidade Pública; Percepção.

\section{Josedilton Alves Diniz}

Doutor em Controladoria e Contabilidade pela USP e Professor da Universidade Federal da Paraíba e Auditor/TCEPB. Contato: Cidade Universitária, João Pessoa-PB CEP: 58.051-900. E-mail: josedilton@gmail.com

\section{Suzany Ferreira}

Silvestre da Silva

Bacharel em Ciências Contábeis pela UFPB e Contadora da Universidade Federal da Paraíba. Contato: Cidade Universitária, João Pessoa-PB CEP: 58.051-900.

E-mail: suzanynany@gmail.com

Leandro da Costa Santos Graduando em Ciências Contábeis pela UFPB. Contato: Cidade Universitária, João Pessoa-PB CEP: 58.051-900. E-mail: leandrosantoscon@@gmail.com

Vinícius Gomes Martins Mestre em Ciências Contábeis pelo Programa Multiinstitucional e Inter-Regional de Pós-Graduação em Ciências Contábeis - UnB/UFPB/UFRN, Doutorando em Ciências Contábeis pelo UnB/UFPB/UFRN e Professor do Centro Universitário de João Pessoa. Contato: Unipê BR 230, Unipê - BR 230, Água Fria. João Pessoa-PB, CEP: 58053-100. E-mail: viniciuscontabeis@hotmail.com 


\section{Introdução}

A atual ordem econômica vem fortalecendo a interdependência dos países e ao mesmo tempo, exigindo padrão de informação financeira comum. Isso tem sido influenciado devido ao progresso tecnológico na área de comunicação, ao avanço nos meios de transportes e ao crescimento do comércio internacional que tem aproximado cada vez mais o mundo nas últimas décadas. Dessa maneira, conforme salientam Mapurunga, Meneses e Peter (2011), desenvolveu-se um movimento mundial em prol da convergência internacional das normas contábeis, objetivando maior comparação e compreensão das informações apresentadas nos diferentes países, tanto na contabilidade aplicada ao setor privado como ao setor público.

Dentro deste contexto, surgiram as International Financial Reporting Standards (IFRS), conjunto de normas, emitidas e revisadas pelo Iasb - International Accounting Standards Board, que visam uniformizar procedimentos contábeis e políticas contábeis entre países. As IFRS foram a base para o desenvolvimento das International Public Sector Accounting Standards - Ipsas, conforme esclarecem Christiaens, Reyniers e Rollé (2010), evitando assim a necessidade de criar novos conceitos para a contabilidade aplicada ao setor público.

As Ipsas têm como objetivo melhorar as informações da contabilidade aplicada ao setor público, permitindo a comparabilidade e a instrumentalização do controle social das entidades estatais, tornando possível o entendimento das informações geradas a partir da escrituração e evidenciá-las nos demonstrativos contábeis, provocando profundas mudanças na gestão, quer no modo de gerir o patrimônio público, quer na forma de reconhecimento, mensuração e evidenciação de itens patrimoniais.

Comungando desta ideia, Pina e Torres (2003, p. 335) entendem que a justificativa para aplicação das normas internacionais de contabilidade na área pública é a de que, com esse padrão, a entidade pública poderia fornecer informações mais precisas sobre a mensuração de bens patrimoniais e de custos dos serviços públicos.

Seguindo este norte, Kohama (2009) comenta que, além de ser complexa, a contabilidade aplicada ao setor público é de suma importância, pois ela controla, registra e interpreta os fenômenos que afetam o orçamento, as finanças e o patrimônio de cada entidade de direito público. Por outro lado, essa complexidade ganha contornos de destaque quando se observa a quantidade de usuários da informação que a contabilidade aplicada ao setor público possui, ou seja, toda a sociedade. Assim, desenvolver modelo de comunicação com a sociedade para que esta possa exercer o controle social é tarefa complexa.

O Brasil vem passando por processo de mudanças na busca de harmonização das normas contábeis do setor público, adequando-se às normas internacionais. De acordo com Mapurunga, Meneses e Peter (2011, p. 98), esse processo tem sido conduzido pelo esforço mútuo entre:

O Conselho Federal de Contabilidade, juntamente com a Secretaria do Tesouro Nacional, os Tribunais de Contas Estaduais, as Instituições de Ensino Superior e demais representantes das esferas Federal, estadual e municipal, que mobilizaram-se, a fim de inserir o processo de convergência das normas internacionais de Contabilidade aplicadas ao setor público, no Brasil. (2011, p. 98)

A Secretaria do Tesouro Nacional, na ausência do conselho de gestão fiscal, previsto no Art. 67 da LRF, assumiu a condição de Órgão Central do Sistema de Contabilidade Federal, no intuito de consolidar as contas dos entes da Federação, além disso, apropriou-se da inexistência da regulação da LRF para ser o órgão normatizador, temporário, da Casp. Para cumprir com essa função, editou a Portaria nº. 109/2011, criando o Grupo Técnico de Padronização de Procedimentos Contábeis (GTCON), dispondo sobre sua composição e funcionamento.

Este grupo técnico, formado por todos os segmentos representativos da contabilidade governamental, detém a responsabilidade de analisar e elaborar diagnósticos e estudos visando à padronização mínima de conceitos e práticas contábeis, plano de contas e classificação orçamentária de receitas e despesas públicas no âmbito da União, estados, Distrito Federal e municípios.

Em observação oportuna, Paludo (2012) alerta que a mudança provocada pela convergência às Ipsas, além de promover desafios, exige que os profissionais se preparem para se adaptar aos padrões mun- 
diais. Nesse sentido, o GTCON tem grande responsabilidade na definição da Casp, e, principalmente, na redução das divergências, em benefício da transparência da gestão fiscal, da racionalização de custos nos entes da Federação e melhoria da qualidade da informação contábil.

Assim, investigar a visão que os membros desse grupo técnico tem acerca de todo esse processo de convergência das normas de contabilidade aplicadas ao setor público, pode ser essencial para a compreensão dos desdobramentos da implantação das Ipsas. Dessa forma, o norte dessa pesquisa é responder à seguinte questão: Qual é a percepção dos profissionais contábeis do GTCON quanto às vantagens na implantação das normas internacionais de contabilidade aplicadas ao setor público no Brasil?

Nesse sentido, o objetivo geral da pesquisa é avaliar a percepção dos membros do GTCON quanto às vantagens da implantação das normas internacionais de contabilidade aplicadas ao setor público no Brasil. Neste limiar, considerando a contribuição para uma melhor compreensão da visão dos participantes do GTCON, a carência de se ter noção sobre o processo de adaptação destas normas na administração pública, a escassez de estudos sobre o tema, além da contribuição não só para a classe contábil em geral, como também para a sociedade como um todo, percebe-se a relevância e justificativa da presente pesquisa.

O presente estudo está dividido em cinco seções, incluindo esta introdução. A segunda seção apresenta uma revisão de literatura, destacando o contexto atual da harmonização das normas contábeis, as Ipsas no Brasil e no mundo e o modelo teórico e hipóteses de pesquisa. Na terceira seção, são apresentados os aspectos metodológicos da pesquisa e os resultados são abordados na quarta seção. Por último, a quinta seção apresenta as principais conclusões do estudo acompanhada das referências utilizadas.

\section{Referencial teórico}

\subsection{Convergência das Normas Internacionais de Contabilidade Aplicadas ao Setor Público}

O complexo fenômeno da globalização, impulsionado pelas revoluções nos transportes, na comunicação e nos avanços na tecnologia da informação, tem expandido as operações empresariais em vários países, na qual a troca e disseminação de ideais tem gerado consequentemente, uma integração entre eles.

A normatização contábil, juntamente com a própria contabilidade, tem sofrido um processo de constante evolução, mostrando-se totalmente influenciável pela cultura, pela economia, pelo pensamento jurídico, pelo poder, pelos interesses em jogo, e etc. (Martins, Martins \& Martins, 2007, p. 8)

Neste norte, Agostino, Drago e Silipo (2011, pp.437- 438) afirmam que se há eventos econômicos de mesma natureza entre os países, então esses eventos devem ser reportados de forma consistente e em modelos semelhantes de evidenciação, com isso as demonstrações financeiras se amoldam a um padrão de informação que permite fazer comparações mais acuradas. Assim, deu-se início à internacionalização das normas contábeis, que surge da necessidade de uniformização, a fim de minimizar os diferentes critérios e práticas adotados por cada país para reconhecer e mensurar cada transação.

O objetivo da padronização conforme salienta Niyama (2005), é "a quebra de fronteiras e de obstáculos entre os países, tornando as informações mais inteligíveis aos vários usuários”. Desse modo, conforme salientam Lemes e Carvalho (2010), a adoção de uma única contabilidade a nível mundial evitará a existência de vários estágios de adoção de normas e publicações de relatórios financeiros.

Neste contexto, nasceu o International Accounting Standards Committee (Iasc), órgão independente, instituído em 1973 e reestruturado em 2001, quando passou a se chamar International Accounting Standards Board (Iasb), detendo como missão, desenvolver as IFRS - International Financial Reporting Standards, um único conjunto de padrões contábeis de alta-qualidade, convergentes e aceitos mundialmente (Alexander \& Jermakowicz, 2006).

O desenvolvimento das Normas Internacionais de Contabilidade Aplicadas ao Setor Público teve seu início em 1997 com o Public Sector Committee (PSC), do International Federation of Accountants (Ifac), criado em 1986. Posteriormente, o PSC teve seu nome alterado para International Public Sector Accoun- 
ting Standards Board (IPSASB), tendo o objetivo de emitir Normas Internacionais de Contabilidade Aplicadas ao Setor Público, assim como promover a aceitação e a convergência internacional destas normas.

Considerando que a convergência aos padrões internacionais possibilita a comparação entre as demonstrações contábeis, este processo se instaurou também no setor público, buscando agregar capacidade informacional a estas demonstrações (Mapurunga, Meneses \& Peter, 2011, p. 97)

Baseadas nas normas internacionais de contabilidade aplicadas ao setor privado (IFRS), surgiram as chamadas International Public Sector Accounting Standards (Ipsas). Estas normas tornaram-se referências internacionais para avaliar as práticas contábeis do governo em todo o globo (Chan, 2008, Christiaens, Reyniers \& Rollé, 2010).

As Ipsas são pronunciamentos que, de forma geral, determinam um conjunto completo de demonstrações a serem elaboradas, visando orientar e harmonizar a contabilidade aplicada ao setor público nos mais diversos países, com o propósito de proporcionar transparência, eficiência e qualidade às informações repassadas.

A implementação destas normas poderá ocasionar diversas mudanças no setor público, principalmente no que tange ao aumento na transparência das informações, bem como na eficiência e na eficácia das ações governamentais. Nesse norte, conforme argumentam Hendriksen e Breda (1999), a Contabilidade, como ciência da informação, constitui ferramenta essencial, pois permite que os gestores possam alcançar seus objetivos de forma hábil, uma vez que fornece informações que tornam as decisões tomadas mais acertadas.

Todavia, é interessante ressaltar que o processo de harmonização da contabilidade no setor público também é precedido de diversos obstáculos e desafios, conforme Brusca e Condor (2002, p. 154) destacam, tais como a ampla importância que o sistema jurídico desempenha sobre a contabilidade aplicada ao setor público, proveniente da importância do orçamento, assim como as normas que o regulam; diferenças linguísticas e culturais nos diferentes países; diferenças no desenvolvimento econômico do país; o nacionalismo enraizado, no qual cada país considera o seu sistema contábil o mais adequado; e o tradicionalismo geral das administrações públicas na questão da mudança.

Desta maneira, com vistas a aperfeiçoar as informações contábeis, o Brasil se encontra em processo de convergência às Normas Internacionais de Contabilidade Aplicadas ao Setor Público, visando à eliminação de diferenças entre os padrões nacionais e internacionais, buscando elevar a transparência na gestão pública, assim como admitir a comparabilidade das informações produzidas.

\subsection{Reflexos da convergência no Brasil}

No Brasil, o procedimento de convergência teve início com a publicação, em 2004, da Portaria CFC $\mathrm{n}^{\circ}$. 37/2004, que discorre sobre o processo de harmonização das Normas Internacionais de Contabilidade Aplicadas ao Setor Público, com a formação de um grupo de estudos na área pública que tinha por objetivo estudar e analisar as Normas Brasileiras de Contabilidade Aplicadas ao Setor Público (NBCASP), paralelo às Ipsas, criadas pelo Ifac. O grupo era composto por membros do CFC, Secretaria do Tesouro Nacional (STN) e Secretaria Executiva do Ministério da Fazenda.

Segundo Varandas (2013, pp. 14-15), o Grupo Técnico, criado pelo CFC, "tinha inicial função de tradução e validação das Ipsas e, a partir do ano de 2010, deveria elaborar e discutir minutas para implantação das normas internacionais no Brasil". Ao ponderarem sobre o estágio de convergência conceitual entre as Normas Brasileiras de Contabilidade Aplicadas ao Setor Público e as Ipsas, Fragoso, Macêdo, Gusmão Lopes, Ribeiro e Perdeneiras (2012) concluíram que existiam vários aspectos a serem debatidos para uma concreta convergência às normas internacionais.

Conforme demonstra a literatura, a implantação das Ipsas no Brasil segue enfrentando desafios e contratempos, pois o início para sua adoção já foi prorrogada várias vezes por diversos motivos, os quais se podem citar: dificuldade na capacitação dos profissionais e na aceitação dessas mudanças, adaptação à nova fase da Contabilidade no Brasil, com a criação de novos instrumentos de informação e controle do Sistema Público e etc. 
Neste prisma, a Secretaria do Tesouro Nacional (STN), na condição de órgão central do Sistema de Contabilidade Federal, no intuito de consolidar as contas dos entes da Federação, editou a Portaria nº. 109/2011, que criou o Grupo Técnico de Padronização de Procedimentos Contábeis (GTCON), dispondo sobre sua composição e funcionamento. Essa Portaria foi revogada posteriormente pela Portaria $n^{\circ}$. $510 / 2014$, que se encontra em vigor.

As atribuições do GTCON estão dispostas no Art. $1^{\circ}$, da Portaria STN n ${ }^{\circ} .510 / 2014$, entre as quais pode-se destacar a análise e elaboração de estudos e diagnósticos, a apreciação das alterações do Manual de Contabilidade Aplicada ao Setor Público (MCASP), elaboradas pelo órgão central de Contabilidade da União, visando à sua atualização permanente e à responsabilidade de propor a edição de instruções de procedimentos contábeis ou o aprimoramento das já existentes.

Cabe salientar que o GTCON possui caráter técnico e consultivo, manifestando-se por meio de recomendações, devendo nortear-se pelo permanente diálogo, tendo em vista a redução de divergências, beneficiando, assim, a transparência da gestão fiscal, a racionalização de custos nos entes da Federação e o controle social (Brasil, 2014).

Desta forma, conforme se desenrola o processo de convergência aos padrões internacionais de contabilidade aplicados ao setor público, o GTCON torna-se peça fundamental nesta mudança, tendo em vista suas responsabilidades e características. Destaca-se que seus componentes são das mais variadas formações acadêmicas e atuações no mercado, o que ocasiona uma maior abrangência nas soluções específicas para os problemas enfrentados pela harmonização, assim como para a sistematização das normas de contabilização do setor público.

Muitos são os estudos sobre a internacionalização das normas contábeis aplicadas ao setor público como os de Benito, Brusca e Montesinos (2007), Chan (2008), Christiaens, Reyniers e Rollé (2010), Oulasvirta (2013), Toudas, Poutos e Balios (2013), além dos já citados no presente estudo, não exaurindo a lista de pesquisadores. Todavia, esses estudos se encontram centrados no processo legal de harmonização dessas normas, e não focam na percepção dos agentes envolvidos. Destaca-se que os estudos sobre o prisma da percepção dos profissionais de contabilidade, a respeito da implementação das normas internacionais de contabilidade aplicada ao setor público, são escassos e, na maioria das vezes, de caráter exploratório.

Haller e Keppler (2002) enfatizam que as normas internacionais de contabilidade só poderão cumprir o seu objetivo, de garantir a fiabilidade e comparabilidade da informação contábil, quando corretamente interpretadas e aplicadas por quem elabora e prepara as demonstrações financeiras, ou seja, para que as Normas Internacionais de Contabilidade Aplicadas ao Setor Público tenham o efeito esperado, é necessário que haja uma correta interpretação e aplicação por parte dos profissionais e órgãos públicos competentes.

Nesse norte, cabe ressaltar que, dentre os estudos sobre a compreensão da percepção dos profissionais de contabilidade, destacam-se os de Joshi, Bremser e Al-Ajmi (2008), que chegaram à conclusão de que, na visão dos entrevistados, haverá desafios na aplicação das normas contábeis baseadas em princípios e uma demanda crescente por orientação.

No mesmo horizonte, Bozkurt, Islamoğlu e Öz (2013) comentam que descobrir as diferenças na percepção dos interessados em contabilidade aplicada ao setor público, vai ajudar no estudo de como reduzi-las. Os resultados alcançados por estes pesquisadores demonstram que os entrevistados acreditam que as instituições públicas devem desempenhar o papel principal na adaptação e treinamento das normas internacionais. Salientando que, para o alcance dos benefícios e vantagens proporcionados pela internacionalização das normas contábeis, é necessário dos usuários a percepção, a interpretação, o entendimento e a responsabilidade pela prática.

Neste limiar, a análise da percepção do GTCON sobre as vantagens da implantação das Ipsas, para os entes públicos do Brasil, é de clara relevância para que se obtenha os benefícios e vantagens na sua implantação, principalmente pelo fato de que diante do processo de convergência são encontrados alguns desafios, conforme demonstrado pela literatura apresentada, proporcionados, consequentemente, pela cultura, estrutura política, econômica e social e a consequente relutância a mudanças. 


\subsection{Modelo teórico e hipóteses de pesquisa}

As diretrizes indicadas pela nova gestão pública e reformas exigidas para a contabilidade aplicada ao setor público nos países ocidentais são amplamente discutidos na literatura internacional (Guthrie, 2005) e (Olson, Guthrie \& Humphrey, 1998), enquanto pouco se sabe sobre reformas semelhantes e seus resultados nos países em desenvolvimento e países com economias em transição.

A retórica de que as reformas vão melhorar a eficiência, a transparência e a prestação de contas das organizações do setor público por meio da adoção de técnicas de contabilidade do setor privado ainda não está clara - principalmente no Brasil, onde a convergência das normas contábeis está em fase embrionária.

A institucionalização de novas visões para a mudança das práticas contábeis das organizações, bem como de institucionalização das práticas mais antigas moldadas pelas tradições, depende de ampla discussão entre todos os atores envolvidos nesse processo. O processo de traduzir visões em mudanças práticas requer a presença ativa da, denominada por Antipova e Bourmistrov (2013, p.447), "comunidade epistêmica", ou seja, os membros da comunidade técnica que têm a capacidade de mediar a institucionalização e os processos de desinstitucionalização e de promover a aprendizagem organizacional.

Assim, a ideologia por trás do desenvolvimento de sistemas internacionais de contabilidade instituídos pelas Ipsas pode ser entendida em termos de um conjunto neutro e uniforme de normas baseadas nas teorias contábeis desenvolvidas pela profissão contábil na tradição anglo-saxônica, e ainda pode ser universalmente aplicado em qualquer país do mundo. No entanto, conforme afirmam Antipova e Bourmistrov (2013, p.445), a contabilidade do setor público nos países em desenvolvimento com economias em transição tem raízes históricas únicas.

Assim, cabe à "comunidade epistêmica" estimular a exploração de velhas certezas encontradas na tradição, bem como a exploração, por meio da experimentação, com novas soluções fundadas em novas ideias. Esse modelo é mais aplicado para fornecer uma compreensão das reformas requeridas pela contabilidade do setor público brasileiro. No Brasil, conforme se depreende do contexto acima, a "comunidade epistêmica" é representada pelo GTCON.

Segundo Bozkurt, Islamoğlu e Öz (2013), a concepção e implementação de um modelo contábil aplicado ao setor público nacional dependeria de como se dará esse processo. Assim, as vantagens de sua efetiva aplicação podem depender da visão e da expectativa expressas na percepção dos membros do corpo técnico que indicará os caminhos a serem trilhados.

O modelo apresentado por Bozkurt, Islamoğlu e Öz (2013) tem a seguinte configuração:

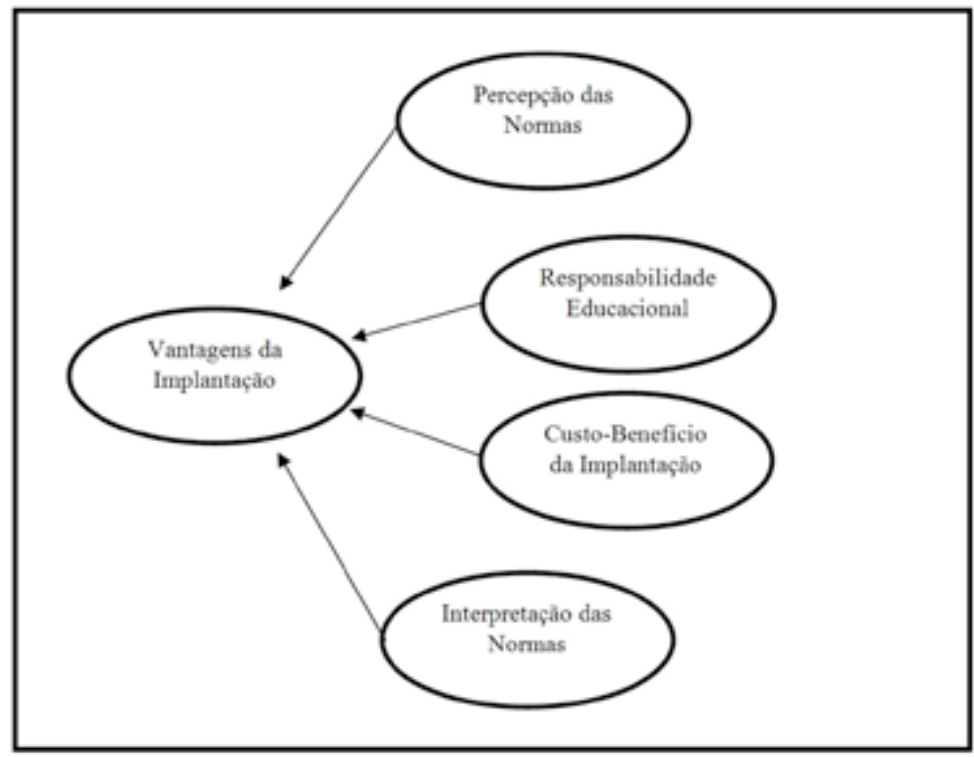

Figura 1. Modelo teórico da pesquisa.

Fonte: adaptado de Bozkurt et al. (2013) 
Pelo o que se coliga do modelo proposto, as vantagens na implementação das Ipsas dependem das expectativas expressas na percepção dos membros do GTCON, quanto à percepção, à interpretação, a o custo-benefício e à responsabilidade educativa na implantação das Ipsas na contabilidade pública brasileira, que indicará os caminhos a serem trilhados.

O construto referente à percepção das normas está ligado ao juízo consciencioso de como o GTCON qualifica as Ipsas de acordo com a sua utilidade, uma vez que é de sua responsabilidade a análise e elaboração de diagnósticos e estudos visando à padronização mínima de conceitos e práticas contábeis relacionadas a estas normas. Logo, o entendimento mais nítido das Ipsas, no que tange à sua utilidade para a gestão pública, no que trata a melhoria da informação contábil no futuro, converge para o aumento das vantagens esperadas na sua implantação.

No tocante ao construto interpretação e aplicação das normas, Rosa (2014) destaca que se faz imprescindível a correta interpretação das normas, pois inexiste uma que se cubra de certeza no que tange ao seu conteúdo, ressaltando que o GTCON tem caráter técnico e consultivo, manifestando-se por meio de recomendações, tendo em vista a redução de divergências. Neste norte, Joshi, Bremser e Al-Ajmi (2008) salientam que "um único conjunto de normas não irá resultar em aumentos substanciais na uniformidade a menos que haja um entendimento comum". Assim, tem-se que a ampliação do conhecimento pela interpretação e aplicação das Ipsas, diante da compreensão de que elas são baseadas em princípios e necessitam de uma interpretação comum, estabelecida, preferencialmente, em parceria com todas as instituições envolvidas nesse processo de convergência, aumentam as vantagens na sua implementação.

Já no que diz respeito à ponderação do custo-benefício da implementação das Ipsas, cabe ressaltar que o GTCON detém, como um dos objetivos, a racionalização de custos nos entes da Federação e o controle social. Segundo Padoveze (2000), o conceito de valor da informação está relacionado com a relação custo-benefício gerado, de modo que, para que se venha a medir seu valor, é necessário que se disponha da informação e que esta venha a reduzir suas incertezas.

Então, para que a informação seja considerada útil e detenha a qualidade de relevante, é necessário, do indivíduo, o entendimento de que os benefícios esperados superam os custos. Neste horizonte, o construto teórico sustenta que a compreensão de que os benefícios esperados são maiores do que os custos empregados na implantação das Ipsas aumentam as vantagens na sua aplicação, o que contribui para criação de valor, acrescendo os benefícios e permitindo a cooperação em escala internacional.

Outro construto teórico que depende da visão e da expectativa expressa na percepção dos membros do GTCON é o que versa sobre a responsabilidade educacional, ou seja, a quem acomete a responsabilidade para a capacitação e para a aplicação das Ipsas. Em sua pesquisa, Padrones, Colares e Santos (2014), ao se questionarem sobre que nível se encontra a implantação das Ípsas, afirmaram que a responsabilidade educativa sobre tal implementação deve ser feita pelo órgão que regula a contabilidade no país, e que entre os fatores principais que dificultam a sua implementação se encontra a falta de orientação e treinamento.

Em pesquisa similar constante nos estudos da PwC (2013), tal problema é apontado, também, como uma das principais dificuldades encontradas no processo de implementação destas normas. Destarte, a percepção dos membros do GTCON a respeito da responsabilidade educacional poderá indicar os caminhos técnicos a serem trilhados para a obtenção de vantagens na implementação das Ipsas.

Como apresentado no modelo teórico, todos os construtos convergem para a efetiva obtenção de vantagens na implementação das Ipsas, tendo em vista que estas poderão proporcionar melhoria nos controles, maior comparabilidade dos demonstrativos, redução de possíveis fraudes e aumento da credibilidade das informações. (PwC, 2103, Padrones, Colares \& Santos, 2014).

Assim, diante desse cenário teórico, definiram-se quatro hipóteses, com a finalidade de propor ou direcionar as respostas à pesquisa proposta. As hipóteses foram testadas a partir do questionário instituído e adaptado de Joshi, Bremser e Al-Ajmi (2008) e Bozkurt, Islamoğlu e Öz (2013). São elas: 
H1: Percepção das Normas: o entendimento mais nítido das Ipsas, proporcionam maior eficácia em sua implementação.

H2: Interpretação das Normas: a ampliação do conhecimento por meio da interpretação e aplicação de conceitos a um problema específico aumentam as vantagens esperadas na aplicação das Ipsas.

H3: Custo-benefício da implantação: a ponderação dos benefícios esperados é maior do que os custos empregados na implantação das Ipsas.

H4: Responsabilidade Educativa: o entendimento comum entre as instituições e os profissionais da contabilidade no desenvolvimento educacional das Ipsas aumenta as vantagens desejadas na sua implementação.

Dessa forma, como se depreende os estudos de Joshi, Bremser e Al-Ajmi (2008) e Bozkurt, Islamoğlu e Öz (2013), a implantação depende da maneira de compreender, interpretar, analisar os custos benefícios gerados e de que forma vai ser o processado da responsabilidade educativa. Desta forma, de acordo com a literatura basilar dessa pesquisa espera-se que a percepção dos atores envolvidos no processo técnico de implantação das Ipsas tenham uma relação direta com os quatros construtos, percepção, interpretação, custos-benefícios e responsabilidade educativa.

\section{Metodologia}

\subsection{Amostra e instrumento de coleta de dados}

Dadas as características do presente estudo, esta pesquisa investigativa embasou-se no procedimento analítico clássico da busca de resultados, advindos, segundo Beuren (2012), das três categorias de pesquisa: quanto aos objetivos, optou-se pela pesquisa exploratória e descritiva; quanto aos procedimentos, pela pesquisa bibliográfica e levantamento ou survey; e, quanto à abordagem do problema, optou-se pelo enfoque quantitativo.

O universo utilizado nesta pesquisa correspondeu aos componentes do GTCON, tanto como membro, como os convidados, que envolvem contadores, auditores, assessores e demais profissionais da contabilidade, totalizando 400 indivíduos. A amostra constou com 108 respondentes, totalizando um percentual de $27 \%$ da população delimitada.

Os dados foram coletados por envio de questionário eletrônico, por e-mail, aos profissionais que atuam no Grupo Técnico de Padronização de Procedimentos Contábeis (GTCON), tendo área de atuação diferenciada, porém com similaridade na função exercida, por exemplo: contador, auditor e auditor fiscal, assessor e analista de diversas áreas. O questionário foi desenvolvido a partir de pesquisas anteriores, aumentando, assim, a confiabilidade dos resultados e a uniformidade do objetivo abordado nesta pesquisa. A maioria das questões propostas têm como base o questionário elaborado e usado por Joshi, Bremser e Al-Ajmi (2008) e Bozkurt, Islamoğlu e Öz (2013)

O questionário está estruturado em seis blocos. O primeiro teve como finalidade a identificação dos respondentes, logo, versou sobre as informações do perfil dos respondentes, como sexo, grau acadêmico, tempo e área de atuação, sendo essas informações de caráter exploratório. O segundo bloco aborda a percepção dos respondentes em relação às Ipsas e à sua aplicabilidade, que foi estruturado de modo a extrair informações para testar a primeira hipótese do estudo. $O$ terceiro refere-se às questões relacionadas à variável dependente do modelo, em que questionaram-se a respeito das principais vantagens que as Ipsas trarão com a sua implantação. O quarto trata sobre os custos e benefícios da implantação das Ipsas, bloco esse que permitiu avaliar a terceira hipótese da pesquisa. O quinto teve a finalidade de capturar informações para o teste da segunda hipótese, assim, tratou sobre a visão dos respondentes a respeito da interpretação e aplicação das Ipsas. O sexto e último bloco buscou extrair informações para testar a hi- 
pótese 4 , logo, procurou-se abordar a opinião dos respondentes sobre a quem deveria ser atribuída a responsabilidade educativa dos contadores e auditores para a aplicação das Ipsas.

Ressalta-se que, a partir do segundo bloco, foi utilizada, nas afirmações do questionário, uma aproximação de uma escala decimal, na qual variou de 1 a 10, sendo que sua pontuação variava entre "discordo totalmente" (1) e "concordo totalmente" (10).

\subsection{Procedimentos estatísticos}

Inicialmente, para validar o instrumento de pesquisa, foi utilizado o modelo definido por Cronbach (1951). Esse modelo tem por finalidade estimar um coeficiente denominado alfa de Cronbach, que é um fator determinante para sua adoção como ferramenta para estimação da confiabilidade por medir a correlação entre respostas em um questionário por meio da análise do perfil das respostas dadas. Trata-se de uma correlação média entre perguntas. Dado que todos os itens de um questionário utilizam a mesma escala de medição, o coeficiente $\alpha$ é adimensional e seu valor flutua ente 0 e 1 , lembrando que valores fora desse intervalo devem ser considerados como escalas sem confiança. Na sequência, foi realizada uma análise exploratória com a descrição dos dados coletados nos questionários, de modo a fornecer uma melhor compreensão das questões abordadas em cada construto do modelo.

Como cada construto do modelo da pesquisa é composto por múltiplas questões, optou-se pela redução da dimensionalidade destas por meio da Análise dos Componentes Principais (ACP). Conforme Lattin, Carroll e Green (2011) , a ACP é um método para se reexpressar dados multivariados. Ela permite que o pesquisador reoriente os dados de modo que as primeiras poucas dimensões expliquem o maior número possível de informações disponíveis. Desse modo, a intuição da utilização da ACP é a redução de variáveis para posterior utilização no modelo de regressão múltipla, modelo este que permitirá testar as hipóteses da pesquisa.

Assim, a partir das dimensões definidas no modelo teórico, o construto empírico utiliza os seguintes componentes principais agrupados: vantagens de implantação; percepção das normas; responsabilidade educacional; custo-benefício da implantação; e interpretação das normas.

Por fim, com o objetivo de testar as hipóteses da pesquisa, fez-se o uso da técnica de regressão linear múltipla, a partir dos componentes principais de cada construto. O modelo estimado é descrito pela Equação 1.

$$
\text { Vant }_{i}=\alpha+\beta_{1} \text { Perc }_{i}+\beta_{2} \text { Cust }_{i}+\beta_{3} \text { Inter }_{i}+\beta_{4} \text { Resp }_{i}+\varepsilon
$$

Em que:

Vant $_{i}=$ vantagens de implantação, extraídas do terceiro bloco do questionário;

$\operatorname{Perc}_{i}=$ percepção das normas, extraídas do segundo bloco do questionário;

Cust $_{i}=$ custo-benefício da implantação, extraídas do quarto bloco do questionário;

Inter $_{i}=$ interpretação das normas, extraídas do quinto bloco do questionário;

$R e s p_{i}=$ responsabilidade educacional, extraídas do sexto bloco do questionário;

$\varepsilon_{i}=$ termo de erro da regressão.

O modelo apresentado pela Equação 1 tem por finalidade testar se as principais vantagens que as Ipsas trarão com a sua implantação, expressas pelos membros do GTCON, podem ser explicadas pela percepção dos mesmos quanto às Ipsas e à sua aplicabilidade (Perc), custo-benefício da implantação das IPSAS (CB), interpretação das Ipsas (Inter) e quanto à responsabilidade educativa dos contadores e auditores para a aplicação das Ipsas. As hipóteses foram testadas a partir da significância das variáveis independentes desse modelo empírico, por meio da estatística $t$. Assim sendo, a primeira hipótese foi testada pela significância da variável Perc, a segunda hipótese foi testada pela significância da variável Inter, a terceira hipótese foi testada pela variável $C B$ e a quarta hipótese foi testada pela significância da variável Res. 
Como as variáveis explicativas do modelo não representam todos os fatores capazes de explicar as vantagens da implantação das Ipsas, devido à impossibilidade de mensuração, é possível que alguma variável (ou fator) omitida possa estar correlacionada com alguma variável explicativa, fato que ocasiona problemas de endogeneidade. Além disso, a simultaneidade correlacional entre a variável dependente e as variáveis independentes também podem levar a problemas de endogeneidade, que, por consequência, leva a parâmetros inconsistentes. Entretanto, o objetivo desse modelo é apenas analisar a relação entre as variáveis de interesse, ou seja, não se tem o objetivo de realizar previsões, logo, esse possível problema pode ser relaxado nas circunstâncias deste estudo (Wooldridge, 2010).

\section{Resultados}

\subsection{Características dos participantes do estudo e confiabilidade do instrumento da pesquisa}

As respostas às perguntas demográficas da pesquisa e as percentagens são indicadas na Tabela $1 . \mathrm{Na}$ primeira questão foi perguntado o sexo. Parte significativa dos profissionais que responderam ao questionário é composta por homens (66,4\%), indicando que a profissão é predominantemente masculina. Em seguida, foi indagado sobre o maior nível de titulação acadêmica e grande parte, $71 \%$, tem pós-graduação. Ao olhar para o tempo de experiência na profissão, a maioria tem mais de 10 anos atuando na profissão, ou seja, 57,9\% dos investigados, sendo que $41 \%$ tem mais de 15 anos de experiência. Foi indagado dos interessados informação sobre a formação acadêmica, como pode ser visto na Tabela 1. A distribuição relacionada com as respostas indicam que parte significativa dos respondentes é composto por contadores, com uma percentagem de $55 \%$ e $28 \%$ são auditores.

Tabela 1

\section{Características dos respondentes}

\begin{tabular}{|c|c|c|}
\hline Características dos respondentes & Respondentes $=107$ & Percentagens \\
\hline Gênero dos profissionais & Total $=107$ & \\
\hline Masculino & 71 & 66,4 \\
\hline Feminino & 36 & 33,6 \\
\hline Grau Acadêmico dos Respondentes & Total $=107$ & \\
\hline Graduação & 28 & 26,2 \\
\hline Especialização & 64 & 59,8 \\
\hline Mestrado & 12 & 11,2 \\
\hline Outros & 3 & 2,8 \\
\hline Tempo de Experiência & Total $=107$ & \\
\hline Menos de 5 anos & 20 & 18,7 \\
\hline $5-10$ anos & 25 & 23,4 \\
\hline $11-15$ anos & 18 & 16,8 \\
\hline Mais de 15 anos & 44 & 41,1 \\
\hline Área de Atuação Profissional & Total $=107$ & \\
\hline Contador & 55 & 51,5 \\
\hline Auditor & 30 & 28,0 \\
\hline Assessor & 4 & 3,7 \\
\hline Outros & 18 & 16,8 \\
\hline
\end{tabular}

Fonte: elaborado pelos autores (2014). 
Para avaliar a confiabilidade do questionário, fez-se o uso do coeficiente alfa de Cronbach. O coeficiente foi calculado levando em consideração todas as questões do instrumento de pesquisa relacionadas à percepção dos respondentes quanto a aceitação e a adaptação das Ipsas, isto é, 18 perguntas.

A Tabela 2 apresenta o resultado do coeficiente estimado. Nota-se que todas as observações foram válidas (casos válidos $=107$ ) e que o coeficiente alfa de Cronbach foi de 0,785. Salienta-se que o valor mínimo aceitável pela literatura do coeficiente é de 0,7 (Leontitsis \& Pagge, 2007), portanto, o resultado sugere evidências de confiabilidade no instrumento de pesquisa utilizado por este estudo.

Tabela 2

Análise de Confiabilidade do Questionário por meio do Alfa de Cronbach

\begin{tabular}{|c|c|c|c|}
\hline & & \multirow[b]{2}{*}{$\mathrm{N}$} & \multirow[b]{2}{*}{$\%$} \\
\hline & & & \\
\hline \multirow{3}{*}{ Casos } & Válidos & 107 & 100,0 \\
\hline & Excluídos & 0 & 0 \\
\hline & Total & 107 & 100,0 \\
\hline \multicolumn{2}{|c|}{ Alfa de Cronbach } & \multicolumn{2}{|c|}{$\mathrm{N}^{\circ}$ de itens } \\
\hline \multicolumn{2}{|c|}{0,785} & \multicolumn{2}{|c|}{18} \\
\hline
\end{tabular}

Fonte: elaborado pelos autores (2014).

\subsection{Análise do resultado do instrumento de pesquisa}

\subsubsection{Análise descritiva}

No que tange à análise da percepção do GTCON quanto à implantação das Ipsas, ficou claro que o GTCON considera que estas normas serão de grande utilidade para a contabilidade aplicada ao setor público, tendo em vista que, de uma forma geral, $84 \%$ dos atores da pesquisa apresentaram-se positivos quanto à utilização das Ipsas. Estes achados reforçam os resultados obtidos por Joshi, Bremser e Al-Ajmi (2008) e Bozkurt, Islamoğlu e Öz (2013), uma vez que, em suas pesquisas, os respondentes se demonstraram otimistas quanto a implementação das normas internacionais e suas vantagens.

As questões que tiveram mais concordância entre os pesquisados foram P1.2 e P1.4, posto que cerca de 94\% dos indivíduos mostraram-se concordantes com as assertivas propostas, revelando que, para a maioria dos respondentes, a implementação das Ipsas irá resolver sérios problemas na contabilidade aplicada ao setor público, proporcionando uma melhoria na qualidade da informação contábil, conforme demonstra a Tabela 3.

Tabela 3

Percepção das IPSAS

\begin{tabular}{|c|c|c|c|c|c|c|c|c|c|c|c|c|}
\hline \multirow{2}{*}{\multicolumn{2}{|c|}{ Assertivas }} & \multicolumn{11}{|c|}{ Grau de Concordância - GC (\%) } \\
\hline & & 1 & 2 & 3 & 4 & 5 & 6 & 7 & 8 & 9 & 10 & GC* \\
\hline P1.1 & $\begin{array}{l}\text { As aplicações das Ipsas serão úteis para a } \\
\text { gestão pública }\end{array}$ & - & - & - & 1 & 5 & 2 & 17 & 22 & 16 & 37 & 94 \\
\hline $\mathrm{P} 1.2$ & $\begin{array}{l}\text { A implantação das Ipsas vai resolver sérios } \\
\text { problemas da contabilidade aplicada ao } \\
\text { setor público }\end{array}$ & - & 3 & 5 & 1 & 14 & 11 & 15 & 21 & 9 & 21 & 78 \\
\hline P1.3 & Ipsas é um alvo inatingível & 2 & 2 & 7 & 7 & 12 & 14 & 9 & 15 & 8 & 23 & 70 \\
\hline P1.4 & $\begin{array}{l}\text { Ipsas irá melhorar a qualidade da } \\
\text { informação contábil no futuro }\end{array}$ & - & - & - & - & 6 & 6 & 4 & 29 & 20 & 36 & 94 \\
\hline & Média & 0 & 1 & 3 & 2 & 9 & 8 & 11 & 22 & 13 & 30 & 84 \\
\hline
\end{tabular}

* Grau de concordância foi calculado com valores da escala superiores a 5.

Fonte: elaborado pelos autores (2014). 
A Tabela 4 evidencia a percepção do GTCON quanto às vantagens na implantação das Ipsas. De forma geral, os respondentes se mostraram otimistas quanto à obtenção de vantagens com a implementação das Ipsas. Para 96\% dos respondentes é certo que as Ipsas farão com que as demonstrações financeiras sejam mais comparáveis no mundo todo (P2.1) e que, para 94\% dos membros do GTCON, as Ipsas contribuirão para o aumento da transparência e da confiabilidade das demonstrações contábeis (P2.2). Quando questionados se os custos irão diminuir significativamente no decorrer do tempo (P2.3), 79\% dos respondentes concordaram com a assertiva.

Quando indagado se as Ipsas poderiam propiciar a redução de atividades ilegais, mais fortemente as fraudes (P2.4), a concordância foi menor, apenas $68 \%$ dos respondentes concordaram, ou seja, cerca de $34 \%$ dos respondentes não estão convictos de que as normas podem contribuir para minimizar as ilegalidades e práticas de fraudes. Algo que chamou atenção nos dados obtidos foi que os auditores acreditam mais na redução das atividades ilegais, especialmente fraudes, do que os contadores, ou seja, $73 \%$ dos auditores concordaram com a colocação enquanto que $50 \%$ dos contadores não acreditam.

Tabela 4

Principais Vantagens da Implantação das Ipsas

\begin{tabular}{|c|c|c|c|c|c|c|c|c|c|c|c|c|}
\hline \multirow{2}{*}{\multicolumn{2}{|c|}{ Assertivas }} & \multicolumn{11}{|c|}{ Grau de Concordância - GC (\%) } \\
\hline & & 1 & 2 & 3 & 4 & 5 & 6 & 7 & 8 & 9 & 10 & GC* \\
\hline P2.1 & $\begin{array}{l}\text { As Ipsas tornarão as demonstrações } \\
\text { financeiras mais comparáveis em } \\
\text { todo o mundo }\end{array}$ & 0 & 0 & 0 & 1 & 3 & 6 & 6 & 19 & 24 & 42 & 96 \\
\hline P2.2 & $\begin{array}{l}\text { As Ipsas contribuirão para melhorar a } \\
\text { transparência e a confiabilidade das } \\
\text { demonstrações contábeis }\end{array}$ & 0 & 0 & 0 & 1 & 5 & 2 & 10 & 28 & 22 & 32 & 94 \\
\hline P2.3 & $\begin{array}{l}\text { Os custos de aplicação das Ipsas } \\
\text { vão diminuir significativamente } \\
\text { ao longo do tempo }\end{array}$ & 0 & 4 & 1 & 3 & 14 & 7 & 14 & 24 & 16 & 17 & 79 \\
\hline P2.4 & $\begin{array}{l}\text { A aplicação das Ipsas pode propiciar } \\
\text { a redução das atividades ilegais, } \\
\text { especialmente fraudes }\end{array}$ & 5 & 1 & 5 & 10 & 11 & 14 & 11 & 20 & 12 & 11 & 68 \\
\hline & Média & 1 & 1 & 1 & 4 & 8 & 7 & 10 & 23 & 19 & 25 & 84 \\
\hline
\end{tabular}

* Grau de concordância foi calculado com valores da escala superiores a 5.

Fonte: elaborado pelos autores (2014).

A Tabela 5 evidencia a percepção do GTCON sobre os custos e benefícios na implantação das Ipsas. A maioria (92\%) concorda que a aplicação das Ipsas trará benefícios na preparação e na utilização das demonstrações financeiras, fazendo com que haja uma boa inter-cooperação em escala internacional. A pesquisa mostrou que, para $81 \%$ dos respondentes, o custo de implementação das Ipsas será apenas o passo necessário para que haja o avanço no sistema público e no produto final (P3.2). Quando indagados sobre a necessidade de se fazer uma relação custo-benefício, 77\% dos entrevistados concordaram com a assertiva, pressupondo, assim, que para alguns o custo deve ser analisado para que os benefícios possam superá-los. Esse achado diverge dos resultados obtidos por Bozkurt, Islamoğlu e Öz (2013), pois, conforme identificam, os respondentes acreditam que os benefícios não superarão os custos. 
Tabela 5

\section{Custos e Benefícios de Implantação das Ipsas}

\begin{tabular}{|c|c|c|c|c|c|c|c|c|c|c|c|c|}
\hline \multirow{2}{*}{\multicolumn{2}{|c|}{ Assertivas }} & \multicolumn{11}{|c|}{ Grau de Concordância - GC (\%) } \\
\hline & & 1 & 2 & 3 & 4 & 5 & 6 & 7 & 8 & 9 & 10 & GC* \\
\hline P3.1 & $\begin{array}{l}\text { A aplicação das Ipsas irá aumentar } \\
\text { os benefícios do uso, permitindo a } \\
\text { cooperação em escala internacional }\end{array}$ & 0 & 0 & 1 & 2 & 6 & 8 & 18 & 28 & 14 & 23 & 92 \\
\hline P3.2 & $\begin{array}{l}\text { As Ipsas trarão mais benefícios do que os } \\
\text { custos esperados de implementação }\end{array}$ & 0 & 1 & 2 & 3 & 13 & 10 & 14 & 25 & 11 & 21 & 81 \\
\hline P3.3 & $\begin{array}{l}\text { É necessário fazer uma análise do custo- } \\
\text { benefício }\end{array}$ & 7 & 1 & 3 & 1 & 12 & 7 & 12 & 17 & 13 & 27 & 77 \\
\hline & Média & 2 & 1 & 2 & 2 & 10 & 9 & 15 & 23 & 13 & 24 & 83 \\
\hline
\end{tabular}

* Grau de concordância foi calculado com valores da escala superiores a 5.

Fonte: elaborado pelos autores (2014).

A Tabela 6 evidencia a percepção do GTCON quanto à importância da interpretação e aplicação das Ipsas. Neste ponto, os respondentes foram mais positivos, ou seja, cerca de $91 \%$ dos respondentes se mostraram favoráveis aos aspectos pontuados nesse grupo de questões. Para $91 \%$ dos respondentes, as Ipsas são preparadas de acordo com alguns princípios (P4.1). Já para que haja um melhor entendimento delas, $85 \%$ responderam que o processo de interpretação deveria ser conduzido por órgãos normatizadores, neste caso o Ifac, a fim de obter uma interpretação mais fiel ao seu propósito inicial. Também foi evidenciada, por 95\% dos profissionais da contabilidade, na (P4.3), a necessidade de realizar uma ação conjunta entre as instituições envolvidas no processo de convergência, a fim de que haja uma compreensão em comum das normas de contabilidade internacionais.

Tabela 6

\section{Interpretação e Aplicação das Ipsas}

\begin{tabular}{|c|c|c|c|c|c|c|c|c|c|c|c|c|}
\hline \multirow{2}{*}{\multicolumn{2}{|c|}{ Assertivas }} & \multicolumn{11}{|c|}{ Grau de Concordância - GC (\%) } \\
\hline & & 1 & 2 & 3 & 4 & 5 & 6 & 7 & 8 & 9 & 10 & $\mathbf{G C}^{*}$ \\
\hline P4.1 & $\begin{array}{l}\text { Acredito que as normas Ipsas } \\
\text { são preparadas de acordo com } \\
\text { certos princípios }\end{array}$ & 0 & 1 & 2 & 2 & 5 & 4 & 7 & 22 & 21 & 36 & 91 \\
\hline P4.2 & $\begin{array}{l}\text { A fim de estabelecer uma interpretação } \\
\text { comum das Ipsas, os órgãos } \\
\text { normatizadores internacionais (como } \\
\text { o Ifac) devem conduzir o processo de } \\
\text { interpretação }\end{array}$ & 3 & 1 & 0 & 2 & 8 & 7 & 9 & 19 & 13 & 37 & 86 \\
\hline P4.3 & $\begin{array}{l}\text { É necessário estabelecer uma } \\
\text { interpretação comum das Ipsas, em uma } \\
\text { base local, com a parceria de todas as } \\
\text { instituições envolvidas no processo de } \\
\text { convergência }\end{array}$ & 0 & 0 & 1 & 0 & 4 & 6 & 3 & 9 & 24 & 53 & 95 \\
\hline & Média & 1 & 1 & 1 & 1 & 6 & 6 & 6 & 17 & 20 & 42 & 91 \\
\hline
\end{tabular}

* Grau de concordância foi calculado com valores da escala superiores a 5.

Fonte: elaborado pelos autores (2014). 
Com as questões dispostas na Tabela 7, procurou-se verificar dos respondentes de quem seria a responsabilidade de transmitir os conhecimentos acerca da implantação das Ipsas. Entre os responsáveis mencionados foram: universidade (P5. 1), conselho de classe (P5.2), esforço do próprio profissional (P5.3) e do Governo (P5.4). Os resultados revelaram que tanto as universidades, os conselhos de classes e o Governo seriam as três instituições que teriam melhores condições para conduzir o processo educativo para implementação das Ipsas. No entanto, na visão de $33 \%$ dos respondentes, a capacitação no processo de implementação não deve ser alcançada por meio de esforço próprio dos profissionais (P5.3). Neste ponto, há uma relação positiva entre os resultados obtidos e a literatura apresentada, em especial as pesquisas realizadas por Joshi, Bremser e Al-Ajmi (2008) e Bozkurt, Islamoğlu e Öz (2013), em que os respondentes acreditam que é necessário um esforço conjunto entre as instituições de ensino, Governo e os profissionais para que as normas venham a apresentar os benefícios esperados.

Tabela 7

Responsabilidade educativa dos contadores e auditores para a aplicação das Ipsas

\begin{tabular}{|c|c|c|c|c|c|c|c|c|c|c|c|c|}
\hline \multirow{2}{*}{\multicolumn{2}{|c|}{ Assertivas }} & \multicolumn{11}{|c|}{ Grau de Concordância - GC (\%) } \\
\hline & & 1 & 2 & 3 & 4 & 5 & 6 & 7 & 8 & 9 & 10 & GC* \\
\hline P5.1 & $\begin{array}{l}\text { A capacitação para a aplicação das Ipsas deve } \\
\text { ser feita pelas universidades }\end{array}$ & 1 & 2 & 3 & 4 & 7 & 10 & 14 & 14 & 13 & 32 & 83 \\
\hline P5.2 & $\begin{array}{l}\text { A capacitação para a aplicação das Ipsas deve } \\
\text { ser fornecida pelo conselho de classe }\end{array}$ & 4 & 0 & 4 & 2 & 7 & 8 & 12 & 11 & 16 & 36 & 84 \\
\hline P5.3 & $\begin{array}{l}\text { A capacitação para a aplicação das Ipsas deve } \\
\text { ser alcançada por meio de esforço próprio } \\
\text { dos profissionais }\end{array}$ & 11 & 5 & 2 & 0 & 15 & 10 & 10 & 15 & 2 & 30 & 67 \\
\hline P5.4 & $\begin{array}{l}\text { A capacitação para a aplicação das Ipsas deve } \\
\text { estar sob a responsabilidade do Governo }\end{array}$ & 4 & 2 & 2 & 1 & 7 & 8 & 14 & 17 & 13 & 33 & 85 \\
\hline & Média & 5 & 2 & 3 & 2 & 9 & 9 & 13 & 14 & 11 & 33 & 80 \\
\hline
\end{tabular}

* Grau de concordância foi calculado com valores da escala superiores a 5.

Fonte: elaborado pelos autores (2014).

\subsection{Redução da dimensionalidade das variáveis com a ACP}

A presente pesquisa aborda quatro construtos relacionados às vantagens de aplicação das Ipsas. Entretanto, cada construto possui pelo menos três variáveis. Com o intuito de reduzir a dimensionalidade dessas variáveis e criar fatores para cada construto, fez-se o uso da Análise de Componentes Principais (ACP).

Para um bom ajuste da ACP, faz-se necessário testar se as variáveis estão altamente correlacionadas. Para isso, utilizou-se o teste de Barlett e o teste de Kaiser-Meyer-Olkin. Os resultados estão evidenciados na Tabela 8. As probabilidades dos testes implicam a não rejeição da hipótese de alta correlação entre as variáveis de cada construto, resultando na adequação dos dados para a utilização da ACP.

Tabela 8

Testes de Correlação entre as Questões dos Construtos

\begin{tabular}{ccc}
\hline Construto & P-valor do Teste de Bartlett & P-valor do Teste Kaiser - Meyer - Olkin \\
\hline Vantagens & 0,000 & 0,627 \\
\hline Percepção & 0,000 & 0,684 \\
\hline Custo-Benefício & 0,000 & 0,491 \\
\hline Interpretação & 0,000 & 0,675 \\
\hline Responsabilidade & 0,000 & 0,557 \\
\hline
\end{tabular}

Fonte: elaborado pelos autores (2014). 
Para a seleção da quantidade de componente principal por construto, fez-se o uso do critério de Kaiser, que consiste em reter o componente que apresentar autovalor superior a 1. A Tabela 9 evidencia os autovalores, a proporção da variância explicada por cada componente e a proporção acumulada. Como se pode perceber, apenas o componente 1 (Com 1) do construto "Vantagens" apresentou autovalor superior a um, explicando $52 \%$ da variância de todas as questões. Isso indica, a partir da regra de Kaiser, que o construto "Vantagem" obteve apenas um componente principal.

Análise similar pode ser feita para os demais construtos, isto é, os construtos "Percepção", "Custo-Benefício" e "Interpretação" obtiveram apenas um componente com autovalor superior a 1, portanto, um componente principal. Apenas o construto da "Responsabilidade" obteve dois componentes principais com autovalores superiores a um, logo, obteve dois componentes principais.

Tabela 9

Componentes Principais dos Construtos do Estudo

\begin{tabular}{|c|c|c|c|c|}
\hline Variáveis & Componentes & Autovalor & Proporção & Acumulado \\
\hline \multirow{4}{*}{ Vantagens } & Com 1 & 2,080 & 0,520 & 0,520 \\
\hline & Com 2 & 0,852 & 0,213 & 0,733 \\
\hline & Com 3 & 0,750 & 0,188 & 0,921 \\
\hline & Com 4 & 0,318 & 0,079 & 1,000 \\
\hline \multirow{4}{*}{ Percepção } & Com 1 & 2,284 & 0,571 & 0,571 \\
\hline & Com 2 & 0,851 & 0,213 & 0,784 \\
\hline & Com 3 & 0,604 & 0,151 & 0,935 \\
\hline & Com 4 & 0,261 & 0,065 & 1,000 \\
\hline \multirow{3}{*}{ Custo-Benefício } & Com 1 & 1,589 & 0,529 & 0,529 \\
\hline & Com 2 & 0,998 & 0,333 & 0,862 \\
\hline & Com 3 & 0,413 & 0,137 & 1,000 \\
\hline \multirow{3}{*}{ Interpretação } & Com 1 & 1,891 & 0,630 & 0,630 \\
\hline & Com 2 & 0,579 & 0,193 & 0,823 \\
\hline & Com 3 & 0,529 & 0,176 & 1,000 \\
\hline \multirow{4}{*}{ Responsabilidade } & Com 1 & 1,749 & 0,437 & 0,437 \\
\hline & Com 2 & 1,065 & 0,266 & 0,704 \\
\hline & Com 3 & 0,695 & 0,173 & 0,877 \\
\hline & Com 4 & 0,49 & 0,122 & 1,000 \\
\hline
\end{tabular}

Fonte: elaborado pelos autores (2014)

\subsection{Resultados do modelo de regressão e teste de hipótese}

Antes de executar a regressão linear para o modelo empírico predefinido, fez-se uma análise da correlação entre as variáveis do modelo, representadas pelos componentes principais de cada construto, com a finalidade de previamente identificar possíveis tendências do modelo como forma de verificabilidade dos achados da pesquisa. 
Tabela 10

Matriz de Correlação

\begin{tabular}{|c|c|c|c|c|c|c|}
\hline & Vant & Perc & Cust & Inter & Resp_1 & Resp_2 \\
\hline Vant & 1 & & & & & \\
\hline Perc &, $767 * *$ & 1 & & & & \\
\hline Cust &, $616 * \star$ &, $529 * \star$ & 1 & & & \\
\hline Inter &, $535 * \star$ &, $527 * \star$ &, $395 * \star$ & 1 & & \\
\hline Resp_1 &, $304 * \star$ &, $263 * *$ & ,133 &, $362 * \star$ & 1 & \\
\hline Resp_2 & ,153 & ,063 &, $246 *$ & , 120 & ,000 & 1 \\
\hline
\end{tabular}

**. Correlação significante ao nível de $1 \%$.

*. Correlação significante ao nível de $5 \%$.

Nota: Vant: Componente principal do construto "Vantagens"; Perc: Componente principal do construto "Percepção"; Cust: Componente principal do construto "Custo-Benefício"; Inter: Componente principal do construto "Interpretação"; Resp1: Primeiro componente principal do construto "Responsabilidade educativa"; Resp2: Segundo componente principal do construto "Responsabilidade educativa".

Fonte: elaborado pelos autores (2014)

Assim, pelo o que se pode observar no modelo, apenas uma das variáveis (resp_2), responsabilidade pela educação continuada dos profissionais contábeis, não se apresentou significante nos níveis de 1\% e 5\%.

Para testar as hipóteses, utilizou-se a regressão linear, porém não com os dados coletados diretamente no questionário, mas aqueles com os valores que foram calculados quando da ACP. Os parâmetros da regressão podem ser visto na Tabela 11:

Tabela 11

Resultados da Regressão

\begin{tabular}{|c|c|c|c|c|}
\hline \multicolumn{5}{|c|}{ Painel A } \\
\hline Variável Explicativa & Coeficiente & Erro padrão ${ }^{1}$ & Estatística $t$ & p-valor \\
\hline C & 0,000 & 0,057 & 0,000 & 1,000 \\
\hline Perc & 0,545 & 0,101 & 5,420 & $0,000 * * *$ \\
\hline Inter & 0,108 & 0,074 & 1,460 & 0,148 \\
\hline Cust & 0,263 & 0,085 & 3,060 & $0,003 * * *$ \\
\hline Resp1 & 0,086 & 0,047 & 1,810 & $0,073 * *$ \\
\hline Resp2 & 0,041 & 0,069 & 0,590 & 0,557 \\
\hline \multicolumn{5}{|c|}{ Painel B } \\
\hline Descrição & Valor & \multicolumn{2}{|c|}{ Descrição } & Valor \\
\hline $\mathrm{R}^{2}$ & 0,670 & \multicolumn{2}{|c|}{ Teste F (Estatística) } & 48,700 \\
\hline $\mathrm{R}^{2}$ Ajustado & 0,654 & \multicolumn{2}{|c|}{ Teste $\mathrm{F}$ ( $p$-valor) } & 0.000 \\
\hline Jarque-Bera (estatística) & 8,107 & & & \\
\hline Jarque-Bera (p-valor) & 0,017 & \multicolumn{2}{|c|}{ Número de Observações } & 107 \\
\hline
\end{tabular}

${ }^{1}$ Erros-padrão robustos a heterocedasticidade. Estatísticas VIF: Perc $=1.70 ;$ Inter $=1.55 ;$ Cust = 1,52; Resp1 = 1,17;

Resp2 $=1,08$, sugerem ausência de multicolinariedade.

*** Significativo a $1 \%$; ** Significativo a $10 \%$.

Fonte: elaborado pelos autores (2014).

Como pode ser visto na Tabela 11, variável dependente, vantagem na aplicação das Ipsas foi regredida com as variáveis independentes (Percepção das Normas, Responsabilidade Educacional, Custo Benefício da Implantação, Interpretação das Normas). Os resultados revelam que as variáveis Percepções das Normas, Custo Benefício da Implantação e Responsabilidade Educacional tiveram seus estimadores significantes e com o sinal esperado. 
Estes resultados indicaram que $\mathrm{H} 1, \mathrm{H} 3$ e $\mathrm{H} 4$ foram estabelecidas como significativo. Ao se observar os estimadores do modelo, pode-se ver que a maior contribuição positiva foi da variável percepção das normas, que apresentou o estimador com magnitude de 0,511 e significativa a $1 \%$. Então, concluiu-se que, para os membros do GTCON a percepção nítida da Ipsas contribui para a obtenção de vantagens na sua aplicação, constituindo-se ferramenta essencial para a gestão pública e melhorando, assim, a informação contábil que tornam as decisões tomadas mais acertadas.

Verificou-se também, de acordo com os achados, que a percepção acerca dos custos-benefícios e responsabilidade educativa dos profissionais da contabilidade foram significativas, contribuindo para a criação de valor e obtenção de vantagens na implantação das Ipsas.

No que concerne à interpretação, realizada de acordo com a análise de regressão de variáveis relacionadas à $\mathrm{H} 2$ (interpretação das normas), ficou claro nos resultados que a percepção do GTCON sobre esta variável não se apresenta como vantagem na implantação das IPSAS, rejeitando-se assim a hipótese vergastada.

Por fim, enquanto a hipótese (H2) Interpretação das Normas, não proporciona para os membros do GTCON vantagens esperadas a partir das aplicações das Ipsas, as hipóteses (H1, H3 e H4) Percepção das Normas, Responsabilidade Educacional e Custo-benefício da Implantação proporcionam vantagens quanto à aplicação de trabalhos colaborativos e entendimento comum acerca da aplicação das Ipsas (Tabela 12).

Tabela 12

Teste de hipóteses

\begin{tabular}{lccc}
\hline \multicolumn{1}{c}{ Hipóteses } & B & p-valor & Avaliação \\
\hline $\begin{array}{l}\text { H1: Percepção das Normas: o entendimento mais nítido das Ipsas, } \\
\text { proporcionam maior eficácia em sua implementação. }\end{array}$ & 0,545 & 0,000 & Não rejeitada \\
\hline $\begin{array}{l}\text { H2: Interpretação das Normas: a ampliação do conhecimento por meio da } \\
\text { interpretação e aplicação de conceitos a um problema específico aumentam as } \\
\text { vantagens esperadas na aplicação das Ipsas. }\end{array}$ & 0,108 & 0,148 & Rejeitada \\
\hline $\begin{array}{l}\text { H3: Custo-benefício da implantação: a ponderação dos benefícios esperados é } \\
\text { maior do que os custos empregados na implantação das Ipsas. }\end{array}$ & 0,263 & 0,003 & Não rejeitada \\
\hline $\begin{array}{l}\text { H4: Responsabilidade Educativa: o entendimento comum entre as instituiç̃̃es } \\
\text { e os profissionais da contabilidade no desenvolvimento educacional das Ipsas } \\
\text { aumentam as vantagens desejadas na sua implementação. }\end{array}$ & 0,086 & 0,073 & Não rejeitada \\
\hline
\end{tabular}

Fonte: elaborado pelos autores (2014).

\section{Considerações Finais}

A presente pesquisa teve como objetivo identificar a percepção dos profissionais que fazem parte do Grupo Técnico de Padronização de Procedimentos Contábeis (GTCON), que são responsáveis pela discussão técnica acerca das vantagens da implantação das normas instituída nas Ipsas para os entes públicos do Brasil. Nesse sentido, utilizou-se como instrumento de pesquisa um questionário cujas indagações foram elaboradas sobre cinco perspectivas teóricas, dentro de um modelo empírico em que há quatro grupos de questões denominadas de variáveis dependentes e um grupo de variável independente.

A heurística colada é na direção de que as vantagens da efetiva implantação das Ipsas dependem de como os membros do GTCON percebem as normas contábeis (Ipsas e NBCT/CFC), de quem vai ser a responsabilidade pelo treinamento educacional dos profissionais da contabilidade, a visão do custo-benefício que as novas regras trarão e quem vai ser responsável pela interpretação das normas contábeis.

Os resultados revelaram que a visão dos membros sobre as Ipsas é propositiva na sua utilização. Os membros do GTCON acreditam que a implementação e aplicações das Ipsas serão úteis para a gestão pública, pois irão resolver sérios problemas nesta área ao proporcionarem vantagens, podendo-se citar: maior comparabilidade dos demonstrativos, redução de possíveis fraudes e aumento da credibilidade das 
informações, proporcionando uma melhor tomada de decisão por parte da administração pública. Um fato relevante dentro desse construto (percepção das normas) é que os atores das pesquisas concordam que a implantação das Ipsas é um alvo capaz de ser alcançado. Salientando que essa variável apresenta uma correlação significante com as vantagens de implantação.

A análise custo-benefício da implantação mostrou-se significativa para a obtenção de vantagens na aplicação das Ipsas, ou seja, na visão do GTCON, a aplicação das Ipsas trarão resultados superiores aos investimentos despendidos, em especial, ao garantir registros contábeis uniformes e consistência dos relatórios obtidos a partir desses registros que estarão disponíveis por meio da compreensão de aplicações dessas normas.

Outro resultado importante desta análise é sobre a quem deve ser acometida a responsabilidade pelo treinamento e aplicação das Ipsas (responsabilidade educativa), no qual, segundo o entendimento do GTCON, deve estar sob a responsabilidade do Estado. Além disso, o resultado obtido a partir de outras questões é que existem expectativas de que as instituições universitárias sejam responsáveis pela capacitação e aplicação das Ipsas. Outro ponto interessante na análise deste construto foi o fato de que os entrevistados não concordam que o treinamento e aplicação das Ipsas devam ser assegurados por esforços pessoais, mas, sim, pelo Governo, ou seja, quanto mais o setor público se responsabilizar pela capacitação das normas, maiores serão as vantagens obtidas, estando este componente, diretamente relacionado com as vantagens de implantação das Ipsas.

Por fim, o componente do construto interpretação das normas, na visão do GTCON, não se mostrou significante para a obtenção de vantagens na implantação e aplicação das Ipsas. A expectativa inicial, traduzida em hipótese de pesquisa, era a de que houvesse uma relação significante e direta entre o construto e a obtenção de vantagens, tendo em vista que, para assegurar uma interpretação comum das IPSAS, instituições reguladoras internacionais como o Ifac e o Gasb, devem desempenhar um papel regulador. Em nível nacional, as instituições como CFC, STN e TCs devem atuar como parceiros para esses estudos. Mesmo com esses apelos teóricos, na prática, os membros do GTCON entenderam diferentemente, uma vez que a hipótese foi rejeitada, ou seja, a forma de como se dará a interpretação das normas não é um fator preponderante para as vantagens de implantação das Ipsas.

Este achado diverge dos resultados obtidos por Joshi, Bremser e Al-Ajmi (2008) e Bozkurt, Islamoğlu e Öz (2013), uma vez que em seus estudos os respondentes assinalaram que a interpretação comum das normas, constitui-se fator essencial para a obtenção de vantagens na sua implementação.

Ante o exposto, o resultado apurado e analisado, percebe-se que, na visão do GTCON, a implantação das Ipsas é positiva e com vantagens para o registro e divulgação das informações econômicas, financeiras e orçamentárias. Também ficou constatado que o Brasil encontra-se em processo de adaptação e aceitação das novas mudanças a serem implantadas no sistema público, mas ainda existem resistências em relação à atualização de seus conceitos e de ir à busca de novos desafios trazidos pela nova fase da Contabilidade Pública.

\section{Referências}

Agostino, M., Drago, D., \& Silipo, D. B. (2011). The value relevance of IFRS in the European banking industry. Review of quantitative finance and accounting, 36(3), pp. 437-457. DOI: 10.1007/s11156010-0184-1

Alexander, D., \& Jermakowicz, E. (2006). A true and fair view of the principles/rules debate. Abacus, 42(2), pp. 132-164. DOI: 10.1111/j.1467-6281.2006.00195.x

Antipova, T., \& Bourmistrov, A. (2013). Is Russian public sector accounting in the process of modernization? An analysis of accounting reforms in Russia. Financial Accountability \& Management, 29(4), pp. 442-478. DOI: $10.1111 /$ faam.12021 
Benito, B., Brusca, I., \& Montesinos, V. (2007). The harmonization of government financial information systems: the role of the IPSASs. International Review of Administrative Sciences, 73(2), pp. 293-317. DOI: $10.1177 / 0020852307078424$

Beuren, I. M. (Org.). (2012) Como elaborar trabalhos monográficos em contabilidade: teoria e prática. São Paulo: Atlas.

Bozkurt, O., Islamoğlu, M., \& Öz, Y. (2013). Perceptions of professionals interested in accounting and auditing about acceptance and adaptation of global financial reporting standards. Journal of Economics, Finance \& Administrative Science, 18(34).

Brasil. Portaria da Secretaria do Tesouro Nacional n 109 (2011, fevereiro 21).

Brasil. Portaria da Secretaria do Tesouro Nacional nº 510 (2014, agosto 28).

Brasil. Lei Complementar no 101 (2000, maio 04).

Brasil. Portaria do Conselho Federal de Contabilidade no 37 (2004, março 11).

Brusca, I., \& Condor, V. (2002). Towards the harmonisation of local accounting systems in the international context. Financial Accountability \& Management, 18(2), pp. 129-162. DOI: 10.1111/1468-0408.00148

Chan, J. L. (2008). International public sector accounting standards: conceptual and institutional issues. The Harmonization of Government, 21, pp. 1-15.

Christiaens, J., Reyniers, B., \& Rollé, C. (2010). Impact of IPSAS on reforming governmental financial information systems: a comparative study. International Review of Administrative Sciences, 76(3), pp. 537-554. DOI: $10.1177 / 0020852310372449$

Cronbach, L. J. (1951). Coefficient alpha and the internal structure of tests. psychometrika, 16(3), pp. 297 334. DOI:10.1007/BF02310555

Fragoso, A. R., Macêdo, J. M. A., de Gusmão Lopes, J. E., Ribeiro Filho, J. F., \& Pederneiras, M. M. M. (2012). Normas Brasileiras e Internacionais de Contabilidade Aplicadas ao Setor Público e o Desafio da Convergência: uma Análise Comparativa-IPSAS e NBCTSP. Revista de Educação e Pesquisa em Contabilidade (REPeC), 6(4), pp. 434-447. DOI: http://dx.doi.org/10.17524/repec.v6i4.260

Guthrie, J. (Ed.). (2005). International public financial management reform: progress, contradictions, and challenges. IAP.

Haller, A., \& keppler, J. (2002). Financial accounting developments in the European Union: past events and future prospects. The European Accounting Review, 1(11), pp. 153-190. DOI: abs/10.1080/09638180220124770

Hendriksen, E. S., \& Van Breda, M. F. (1999). Teoria da contabilidade; tradução de Antonio Zoratto Sanvicente. São Paulo: Atlas.

Joshi, P. L., Bremser, W. G., \& Al-Ajmi, J. (2008). Perceptions of accounting professionals in the adoption and implementation of a single set of global accounting standards: Evidence from Bahrain. Advances in Accounting,24(1), pp. 41-48. DOI:10.1016/j.adiac.2008.05.007

Kohama, H. (2009). Contabilidade pública: teoria e prática. São Paulo: Atlas.

Lattin, J., Carroll, J. D., \& Green, P. E. (2011). Análise de dados multivariados. São Paulo: Cengage Learning.

Lemes, S., \& Carvalho, L. N. (2010). Contabilidade internacional para graduação. São Paulo: Atlas.

Leontitsis, A., \& Pagge, J. (2007). A simulation approach on Cronbach's alpha statistical significance. Mathematics and Computers in Simulation,73(5), pp. 336-340. DOI:10.1016/j.matcom.2006.08.001

Mapurunga, P. V. R.; Meneses, F. de; Peter, M. da G. A. (2011) O Processo de Convergência das Normas Internacionais de Contabilidade: Uma Realidade nos Setores Privado e Público Brasileiros. Revista Controle, 1(11). 
Martins, E., Martins, V. A., \& Martins, E. A. (2007). Normatização contábil: ensaio sobre sua evolução e o papel do CPC. Revista de Informação Contábil, 1(1), pp. 7-30.

Niyama, J. K. (2005). Contabilidade internacional. São Paulo: Atlas.

Olson, O., Guthrie, J., \& Humphrey, C. (1998). Global warning: Debating international developments in new public financial management. Cappelen Akademisk Folag.

Oulasvirta, L. (2013). The reluctance of a developed country to choose International Public Sector Accounting Standards of the IFAC. A critical case study. Critical Perspectives on Accounting, 25(3), pp. 272-285. DOI:10.1016/J.CPA.2012.12.001

Padoveze, C. L. (2000). Sistemas de informações contábeis: fundamentos e análise. São Paulo: Atlas.

Padrones, K. G. de S. A., Colares, A. C. V., \& Santos, W. J. L. dos. (2014, novembro). Análise do grau de implantação das IPSAS nas entidades públicas brasileiras e suas principais limitações no processo. Anais do Congresso Brasileiro de Custos, Natal, RN, Brasil, 21

Paludo, A. (2012). Administração pública: teoria e questões. Rio de Janeiro: Elsevier.

Pina, V., \& Torres, L. (2003). Reshaping public sector accounting: an international comparative view. Canadian Journal of Administrative Sciences/Revue Canadienne des Sciences de l'Administration, 20(4), pp. 334-350.

PWC. (2013) PricewaterhouseCoopers. Towards a new era in government accounting and reporting.

Rosa, L. S. C. L. M. (2014) Da interpretação e da norma penal. Conteúdo Jurídico, Brasília, DF, Brasil.

Toudas, K., Poutos, E., \& Balios, D. (2013). Concept, Regulations and Institutional Issues of IPSAS: a critical review. European Journal of Business and Social Sciences, 2(1), pp. 43-54.

Varandas, R. N. (2013). A presença das IPSAS na construção das Normas Brasileiras de Contabilidade Aplicada ao Setor Público: uma abordagem infométrica. Dissertação de mestrado, Universidade Federal do Paraná, Curitiba, PR, Brasil.

Wooldridge, J. M. (2010). Econometric analysis of cross section and panel data. MIT press. 